\title{
Mechanical Characterization of Nanomaterial Reinforced Aluminum-based Hybrid Nanocomposites
}

\author{
Girisha $\mathrm{L}^{1^{*}}$, Malteshkumar Deshpande ${ }^{2}$, Gururaja Lakshman Naik ${ }^{3}$, Mahanthesh M R \\ ${ }^{1,2,4}$ PES Institute of Technology and Management, Shivamogga \\ ${ }^{3}$ PVP Polytechnic, Bengaluru
}

* Corresponding author email: girisha@pestrust.edu.in

Received: 12 April 2019 / Accepted: 25 May 2019 / Published: 25 May 2019

\begin{abstract}
Nanostructures are viewed as definitive fiber materials as a reinforcement for matrices because of their impressive properties. Because of their phenomenal mechanical properties Carbon nanotubes (CNTs), graphene (GR), and nanodiamond (ND) have made an enormous proportion of intensity in research over the world. Multiwalled carbon nanotubes (MWCNTs), Graphene, and Nano Diamond were utilized as reinforcements for the current work. Nanostructures with their extraordinary strength, minute size, and high aspect ratio were used as reinforcements in commercial-purity Al matrix. These nanocomposites were manufactured by various different routes such as casting and powder metallurgy techniques. Both of these methods are helpful for the preparation of MWCNTs/Al nanocomposites. These nanocomposites were manufactured with various weight fractions of reinforcements and characterized for their mechanical properties and indicated improved properties in contrast with the base $\mathrm{Al}$ matrix. Al/MWCNT nanocomposites, $\mathrm{Al} / \mathrm{MWCNT} / \mathrm{GR}$ hybrid nanocomposites and $\mathrm{Al} / \mathrm{MWCNT} / \mathrm{GR} / \mathrm{ND}$ hybrid nanocomposites samples were tested for their mechanical properties such as Young's modulus, percentage elongation yield strength, and ultimate Strength. Mechanical characterization of these prepared composite samples demonstrated improved strength when compared with the casted samples.
\end{abstract}

Keywords: Carbon nanotubes, Graphene, Nanodiamond, nanocomposites, hybrid composites, tensile properties

\section{Introduction}

Nanotechnology is interdisciplinary of science, engineering and technology. It deals with nanoscale, which ranges from $1-100 \mathrm{~nm}$ in at least one of the dimensions. Nanoscience and nanotechnology are the research areas which are concerned with minute things. Basic science, Human Science, materials science, and engineering are the various scientific fields that might be used in. Nanomaterials are more and more essential product of nanotechnologies. Among the invention of various nanometer size materials, one in all the foremost stable $\mathrm{sp}^{2}$ carbon-bonded materials like helical microtubules of carbon fullerenes [1] and carbon nanotubes (CNTs) [2] have triggered the study in this field of nanocomposites. The 2 major types of Carbon Nano Tubes are - SWNT \& MWNT (Single walled Nano tubes \&Multi walled Nano tubes) which may have very high structural perfection. CNTs were initially found from a method called CVD (Chemical vapor deposition) [3]. Since then, the synthesis strategies of nanotubes are advanced impressively. In the last few years, nanotubes have caught exceptional attention within the analysis space of composites [4]. Arc discharged technique is one of the methods to synthesize CNTs [5] and therefore the mechanical properties were ascertained to be valuable in producing the composites.

Synthesize of the C60 structures have stirred sturdy interest in graphitic structures for example carbon sheets [6]. Their structures seem like geometric enclosures. They're product of carbon atoms, that establish polygonal faces like pentagonal and hexagonal within the cage [7,8]. Cage-like structures were initially found 
Mechanical Characterization of Nanomaterial Reinforced Aluminum-based Hybrid Nanocomposites

to contain 60 carbon atoms. This structure resembles the shape of a football, with each surface of the pentagon being neighbouring to a hexagon. The carbon structure consists of tube-like structures or needlelike circular layers [9]; The hexagons are arranged around the needle axis on each carbon tube. Graphene (GR) is the most famous carbon nanomaterial of the century, possessing good properties such as in-plane structural stiffness and has its own application in composites. Research has demonstrated that work progresses to the total purpose of interest of GR as its exfoliation is crucial. GR is one of the cutting - edge nanomaterials, that was initial isolated at the University of Manchester by Professors [10]. From that point forward, various specialists were excited about this material since it has the flexibility to transform a huge vary of products due to its terribly superior capabilities when it is compared with the existing materials. The mechanisms of CNTs and GR are of primary interest to researchers, along with this Nano diamond (ND) is also a constituent of carbon and it is one of the encouraging nanomaterials for composite material reinforcement. ND is widely used for a particular reasonable ND base resource at the nano scale vary from 1 - $100 \mathrm{~nm}$. [11,12,13]

NDs are produced by a method called as detonation synthesis (NDDS) [14]. NDDSs are equipped for forming isodiametric nanosized 'unbreakable aggregates' which will be used as a good modifying agent for giving increased mechanical characteristics of the filled polymers. Because of its small size and high number of surface atoms, ND has varied uses [15,16,17]. Carbon nanotubes are found to have a high Young's modulus of the order of $1 \mathrm{TPa}$, makes perfect reinforcement for composite materials. Treatment of $\mathrm{CNT} / \mathrm{Al}$ composites, mechanical portrayal and the composite reinforcement are connected to numerous instruments and mechanisms [18]. Hybrid nanocomposites are the current decade's revolution, the most recent trend in composites by adding two or more fillers to the matrix, which exhibits an excellent result and created interest amongst all the researchers [19]. The present paper highlights the concept of Al-based hybrid nanocomposites with three nanoscale materials, namely multiwalled carbon nanotubes (MWCNTs), GR, and NDs. Casting and powder metallurgy methods have been adopted to compare the properties.

\section{Materials and Methods}

\subsection{Materials}

Among all the accessible materials, Al-based MMCs are found to be appropriate materials for structural applications in the field of aircraft and automotive industries, since they possess number of the excellent properties like lightweight, ductility, highly conductive, corrosion resistant and high strength-to-weight ratio. Since entire spotlight has dependably been on PMCs, and exceptionally less work has been achieved out on the MMCs of nanomaterials (MMNCs). MMNCs with carbon - bonded nanomaterials as reinforcement can be expected to indicate a spectacular improvement in the values of stiffness and hardness. $\mathrm{Al}$ is considered as the essential entrant for carbon bond nanomaterials reinforcement. Present research work utilizes commercial-purity $\mathrm{Al}$ as a matrix. Table 1 indicates the chemical compositions for commercial purity Al.

Table 1: Composition of commercial-purity Al (wt.\%)

\begin{tabular}{|c|c|c|c|c|c|c|c|}
\hline $\mathbf{A l}$ & $\mathbf{F e}$ & $\mathbf{S i}$ & $\mathbf{N i}$ & $\mathbf{Z n}$ & $\mathbf{M n}$ & $\mathbf{C u}$ & $\mathbf{M g}$ \\
\hline 99.77 & 0.095 & 0.083 & 0.015 & 0.013 & 0.011 & 0.005 & 0.005 \\
\hline
\end{tabular}

Al-based matrix composite materials possess wide range of applications in the field of aviation, spacecraft, and automobile industries because of their low density. Particulates-reinforced MMC is one among the novel basic structural materials, and persistent development has been observed in recent years because of its exceptional properties and in-depth application prospects within the future. Based on the size and shape of the reinforcement materials and among the several available nanomaterials, here the carbon nanotubes MWCNTs, GR, and ND are considered. CNTs are self-assembling nanostructures; they have received much consideration as exemplary systems for nanoscience and for various applications, along with 
Girisha et al., Adv. Nan. Res.; Vol. 2 Issue 1, pp: 32-41, 2019

composites the other applications embrace battery electrode materials, field emitteves, nano-electronics and nanoscale sensors. The CNTs system has a particular interest in its unique structure and properties, they have very low size $(\sim 0.42 \mathrm{~nm}$ in diameter) and the mechanical properties of the same are as shown in Table 2.

Table 2: Properties of SWCNT and MWCNT

\begin{tabular}{|c|c|c|}
\hline Property & $\begin{array}{c}\text { SWNT } \\
\text { (Single walled Nano Tubes) }\end{array}$ & $\begin{array}{c}\text { MWNT } \\
\text { (Multi walled Nano Tubes) }\end{array}$ \\
\hline Young's modulus $(\mathrm{GPa})$ & 1054 & 1200 \\
\hline Tensile strength $(\mathrm{GPa})$ & 150 & 150 \\
\hline Density $(\mathrm{g} / \mathrm{cm} 3)$ & 2.1 & 2.6 \\
\hline
\end{tabular}

The production of GR is presently a hot research theme, as the manufacturing process of GR defines its mechanical properties \& as a consequence of its applications. It ought to even be noted that there's no single technique for synthesis of GR that yields the foremost ideal properties for each sensible application; hence, a number of production methods of GR have been reported [20]. NDs are synthesized by the different methods such as, high-energy ball milling using high-pressure high-temperature diamond microcrystal, method of detonation, plasma-assisted chemical vapour deposition (CVD), laser ablation etc. Table 3 represents the properties of nanomaterials.

Table 3: The structured properties of nanomaterials

\begin{tabular}{|c|c|c|c|c|c|}
\hline & Dimensions & Length & Thickness & Diameter & Density (g/cc) \\
\hline Fullerene & OD & $<1 \mathrm{~nm}$ & $<1 \mathrm{~nm}$ & $<1 \mathrm{~nm}$ & $\sim 1.7$ \\
\hline SWCNTs & 1D & $\mu \mathrm{m}$ level & - & $0.75-3 \mathrm{~nm}$ & $\sim 2.1$ \\
\hline MWCNTs & 1D & $\mu \mathrm{m}$ level & - & $<100 \mathrm{~nm}$ & $\sim 2.1$ \\
\hline GR & 2D & - & $<1 \mathrm{~nm}$ & - & $\sim 2.2$ \\
\hline ND & 2D & $\mu \mathrm{m}$ level & $\mu \mathrm{m}$ level & - & $\sim 2.62$ \\
\hline
\end{tabular}

\subsection{Fabrication of Nanocomposites}

For the successful processing of composites, uniform distribution of reinforcement in the metal matrix is the main criterion [21,22]. The processing methods which are adopted subjected to make sure negligible injury to composites [23-26]. Since the reinforcements are nanomaterials, the most important task is to disperse nanomaterials systematically within matrix; Based on the nature of the process incorporated, reinforcement of nanomaterials may even be subject to high temperature and stress or molten metals may come into contact. This could cause chemical change, which might successively cause loss of nanomaterials through carbide formation and will have an effect on the properties of the composites favourably or adversely. The methods generally used for the processing of Al matrix composites are as follows.

I. Casting technique

II. Powder metallurgy technique

Initially, 1 Kilogram of commercial purity $\mathrm{Al}$ was allowed to melt in a resistance-heated muffle furnace and casted in a clay graphite crucible. The temperature of the melt was raised to a value of $993 \mathrm{~K}$. Then the $\mathrm{Al}-$ MWCNTs composites were prepared by stir casting technique with different weight percentages like 0.5 wt. $\%, 1$ wt. $\%, 1.5$ wt. $\%$, and $2 \mathrm{wt.} \%$. The Commercially available pure $\mathrm{Al}$ ingot in the furnace was allowed to melt, CNTs added to the melt and mixed with the assistance of a stirring bar. MWCNTs of $0.5 \mathrm{wt} . \%, 1$ wt. $\%, 1.5 \mathrm{wt} . \%$, and $2 \mathrm{wt.} \%$ of CNTs were added to the molten $\mathrm{Al}$ to derive the composites. A 98\% pure $\mathrm{Al}$ with 200-mesh powder was produced by the atomization method with $75 \mu \mathrm{m}$ size and MWCNTs which are used as reinforcement material are procured from Nanoshell, produced by the chemical vapor 
deposition method. The conventional powder metallurgy technique was utilized for syntheses of $\mathrm{Al} / \mathrm{MWCNTs}$ which includes the steps like blending, compaction, and sintering.

The amorphous carbon will influence and even impede the interaction between the nanomaterials, before the first stage of composite preparation, the surface should be clean. Purification is therefore considered an essential phase. In order to achieve that the raw product of nanomaterials was sonicated in ethanol solution for time of $20 \mathrm{~min}$ at room temperature and finally allowed to dry at $120^{\circ} \mathrm{C}$. Ethanol solution at diluted condition was employed to dissolve the catalytic particles and reinforcement particles $\left(\mathrm{CaCO}_{3}\right)$. As $1 \mathrm{gm}$ of $\mathrm{CaCO}_{3}$ once reacts with the $1.26 \mathrm{~g}$ of ethanol throughout the purification and also the latter quantity should be able to get close to $4 \mathrm{~cm}^{3} 30 \%$ ethanol, mutually catalytic particles and the reinforcement can sufficiently be dissolved in increasing volumes of $4 \mathrm{~cm}^{3} 30 \%$ ethanol.

Initially MWCNTs were allowed to disperse in a solvent (ethanol) \& sonicated with the help of Ultra sonication equipment for time of 20 min and then draw off by placing on the copper grid to obtain pure MWCNTs. Thus, obtained MWCNTs are free from impurities and can be used as reinforcement. The mixtures of $\mathrm{Al}$ and MWCNTs powders were uniaxially hard-pressed in a die under a pressure of $130 \mathrm{kN}$. The purpose of powder mixture compaction is to derive billets of size $20 \mathrm{~mm}$ diameter. The derived product immediately after pressing is called green compact. These Green compacts undergo process called Sintering for which they are placed in a furnace, which involves heating of the green compact specimen at high temperature in a controlled atmosphere condition (nitrogen), This helps for prevention of oxidation of parts. The process helps for increasing the bond structure involving the particles and consequently helps for strengthening of the powder-metal compact. The most important factors which govern the sintering process are atmosphere, temperature, and time. Vacuum sintering furnace (resistance type) was used with voltage: $220 \mathrm{~V}-380 \mathrm{~V}$; max. temperature: $1600^{\circ} \mathrm{C}$; working temperature: $800^{\circ} \mathrm{C}$; heating rate: $0-20^{\circ} \mathrm{C} / \mathrm{min}$. Hot extrusion is generally performed at temperatures of $50-70 \%$ of melting point of the metals, the pressure value ranges from 35 to $700 \mathrm{MPa}$.

For lubrication purpose Oil and graphite powders can be utilized for lower temperature conditions and at higher temperatures glass powders are used. This helps the die life to be upgraded. Al/MWCNT samples were extruded at $560^{\circ} \mathrm{C}$ from $20-\mathrm{mm}$ to a diameter of $8 \mathrm{~mm}$ and a length of $120 \mathrm{~mm}$ with $85 \%$ degree of reduction. Pressure of $100 \mathrm{MPa}$ was used for hot extrusion ( $30 \mathrm{KN}$ force) which applied through a hydraulic press. In the same manner, Al_/MWCNT, Al_/MWCNT/GR and Al_/MWCNT/GR/ND hybrid nanocomposites were fabricated.

\subsection{Tensile testing}

The test samples were prepared in accordance with the ASTM 8 standard and a Universal Testing Machine (UTM) was utilized to conduct the Tensile test. The specimen used for the tensile test was having a gauge length of $40 \mathrm{~mm}$, diameter $13 \mathrm{~mm}$ and the reduced diameter of $8 \mathrm{~mm}$. the test was carried out under static loading conditions to determine the yield strength and tensile strength of the material. Both the Hot extruded and casted samples of Al_/MWCNT, Al_/MWCNT/GR, and Al_/MWCNT/GR/ND Hybrid nanocomposites were machined on a lathe to achieve a reasonable required surface finish. These samples of dimension of diameter 4- $\mathrm{mm}$ and gauge length $40 \mathrm{~mm}$ were commercially tested on a UTM for its mechanical properties.

\section{Results and Discussion}

MWCNTs, GR, and ND possesses high aspect ratio, high modulus, and high strength hence these plays a vital role as a reinforcement. The load from the $\mathrm{Al}$ matrix can be transmitted successfully to nanofibers, similar to the randomly oriented short fibers with high strength and modulus. Likewise, high surface area of the the nano materials (CNT)s makes an interface region, which possesses the properties not same as those of the bulk matrix. The commercial-purity Al matrix material was processed and synthesized using casting and powder metallurgy route. The tensile test specimens were having a dimension of $4 \mathrm{~mm}$ in 
Girisha et al., Adv. Nan. Res.; Vol. 2 Issue 1, pp: 32-41, 2019

diameter, $100 \mathrm{~mm}$ in length and with a gauge length of $50 \mathrm{~mm}$. INSTRON machine was used to carry out tension test. The Figure 1 shows the prepared specimen as per standard ASTM E8 standard.

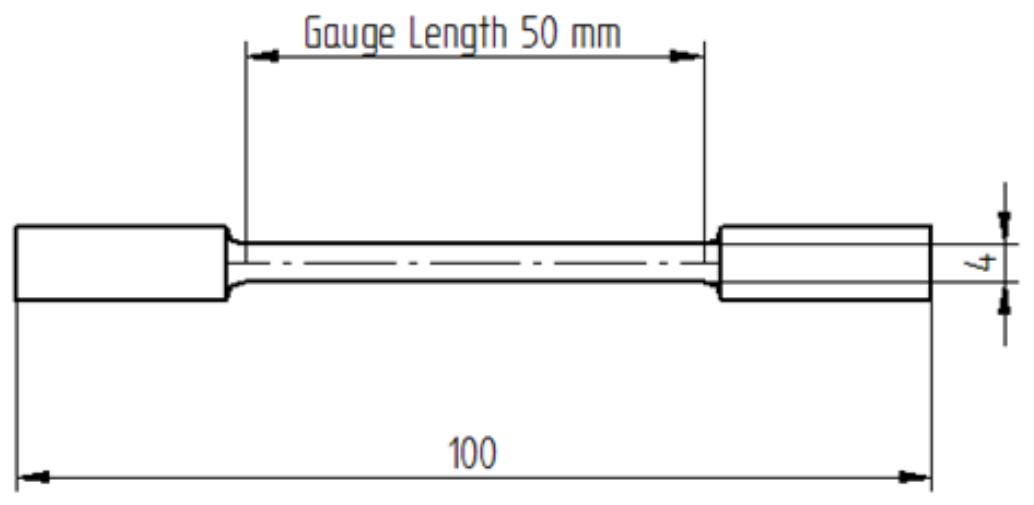

Figure 1: Tensile test specimen

Similar processing conditions and tests were employed for Al_/MWCNT, Al_/MWCNT/GR, Al_/MWCNT/GR/ND hybrid nanocomposites. The Table 4 indicates strength of commercial-purity Al synthesized by casting and powder metallurgy. These properties support basis for assessing the mechanical behavior of the $\mathrm{Al} / \mathrm{MWCNT}$ nanocomposites.

Table 4: Tensile properties of commercial-purity Al

\begin{tabular}{|l|c|c|}
\hline \multicolumn{1}{|c|}{ Property } & Casted & PM \\
\hline Hardness (BHN) & 40 & 44 \\
\hline \% Elongation & 19 & 17 \\
\hline Young's Modulus (GPa) & 69 & 71 \\
\hline Yield Strength (MPa) & 80 & 81 \\
\hline Ultimate Tensile Strength (MPa) & 125 & 126 \\
\hline
\end{tabular}

Table 5 depicts the tensile properties of $\mathrm{Al} / \mathrm{MWCNT}$ nanocomposites; the results illustrates that in comparison with casted samples powder metallurgy samples showed sufficient transfer of the load from the matrix to fiber as shown by increasing trend in Young's modulus and yield strength values with increase in weight percentage of fiber. The ultimate strength of the cast samples does not increase due to the non homogeneous dispersion of reinforcements in the composite and specimen breakage at the grips during the tension test. With increase in reinforcement weight percentage of MWCNTs in Al/MWCNT nanocomposites a downward trend was observed for ductility for both cast and powder metallurgy samples. There was a variation in the hardness up to $1.5 \mathrm{wt} . \%$; thereafter there was no significant change. This was due to the saturation of the reinforcement in the matrix.

Table 5: Tensile properties of Al/MWCNT nanocomposites

\begin{tabular}{|l|l|l|l|l|l|l|l|l|}
\hline \multirow{2}{*}{ Composition } & \multicolumn{2}{|c|}{$\begin{array}{c}\text { Young's Modulus } \\
\text { (GPa) }\end{array}$} & \multicolumn{2}{c|}{$\begin{array}{c}\text { Yield Strength } \\
\text { (MPa) }\end{array}$} & \multicolumn{2}{c|}{$\begin{array}{c}\text { Ultimate Tensile } \\
\text { Strength (MPa) }\end{array}$} & \multicolumn{2}{c|}{ \% Elongation } \\
\cline { 2 - 10 } & Casted & PM & Casted & PM & Casted & PM & Casted & PM \\
\hline Al/1wt.\% MWCNTs & 77.5 & 82 & 95.95 & 97 & 151 & 153 & 9.1 & 8 \\
\hline $\begin{array}{l}\text { Al/1.5wt..\% } \\
\text { MWCNTs }\end{array}$ & 82.72 & 86 & 98.6 & 99 & 152 & 157 & 8.43 & 7.88 \\
\hline $\begin{array}{l}\text { Al/2wt.\% } \\
\text { MWCNTs }\end{array}$ & 84.67 & 85 & 98.2 & 101.3 & 150 & 157 & 7.92 & 7.46 \\
\hline
\end{tabular}

The results for the $1 \mathrm{wt} . \%$ MWCNT-reinforced commercial-purity Al composites depicts that, the value of Young's modulus increased by $12.31 \%$ \& $15.49 \%$ for the specimens prepared from casted and powder metallurgy routes, respectively. The yield strength of the casted and powder metallurgy composite samples 
Mechanical Characterization of Nanomaterial Reinforced Aluminum-based Hybrid Nanocomposites

also improved by $19.93 \%$ and $19.75 \%$ respectively. The results for Young's modulus, yield strength, and ultimate strength for $1.5 \mathrm{wt} . \%$ Al_/MWCNT nanocomposites showed an increase in the value of $19.88 \%$, $23.25 \%$, and $21.6 \%$ for the cast composite samples and $21.12 \%, 22.22 \%$, and $24.60 \%$ for the samples prepared using powder metallurgy respectively.

It was also seen for the $\mathrm{Al}$ composite strengthened by $2 \mathrm{wt} . \%$ MWCNT. The modulus and yield strength of the young show an increase in the matrix value of $22.7 \%$ and $22.75 \%$ for the casted samples, and 19.71 $\%$ and $25.06 \%$ for the samples prepared with powder metallurgy route. Even though improvement was observed for ultimate strength of the matrix, there exists a reduction in the value compared to the $\mathrm{Al} / \mathrm{MWCNT}$ composites for $1 \mathrm{wt} . \%$ and $1.5 \mathrm{wt} . \%$. The increase in strength prompts to a reduction in ductility. Samples prepared from casting route also showed good results for strength and stiffness compared with the powder metallurgy sample.

Because of higher porosity levels and lack of microscopic coherence between $\mathrm{Al}$ and MWCNT, higher numbers of cracks in the composite produced by the cast sample during tensile deformation compared to the powder metallurgy samples as observed from Figure 2. However, Short average length and smaller width of the individual cracks were observed in case of $\mathrm{Al} / \mathrm{MWCNT}$ films because the suppression effect caused by the MWCNTs made it difficult to propagate the cracks. In addition, the effect of MWCNTs on crack propagation restraint is indicated in Figure 3, it is observed that in the vicinity of broken or exposed CNTs indicated as dark ellipses, whereas in the powder metallurgy samples, the crack width is smaller than in the cast samples.

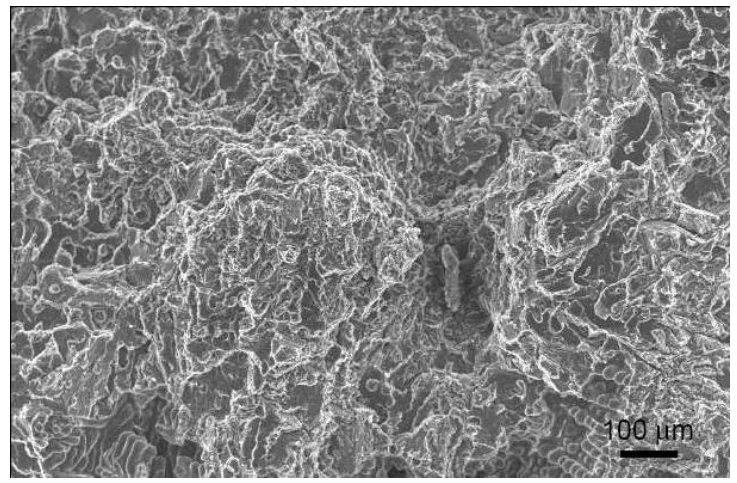

(i)

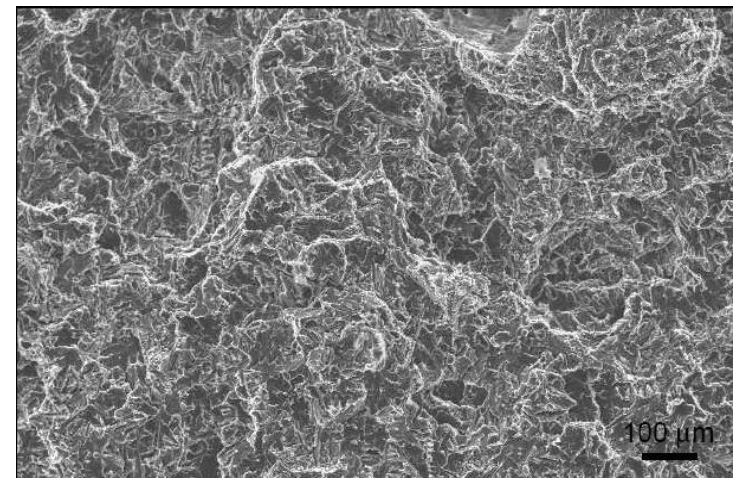

(ii)

Figure 2: SEM image of the fracture surface of an Al with $1 \mathrm{wt} . \%$ MWCNT for tensile test samples: i) casted samples (ii) powder metallurgy samples

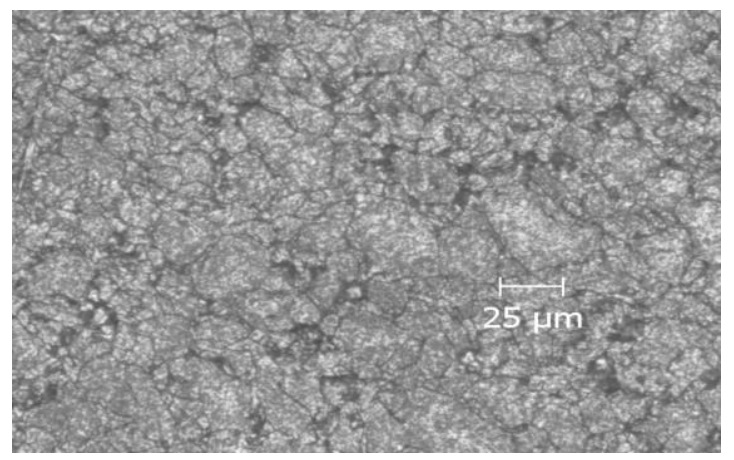

(i)

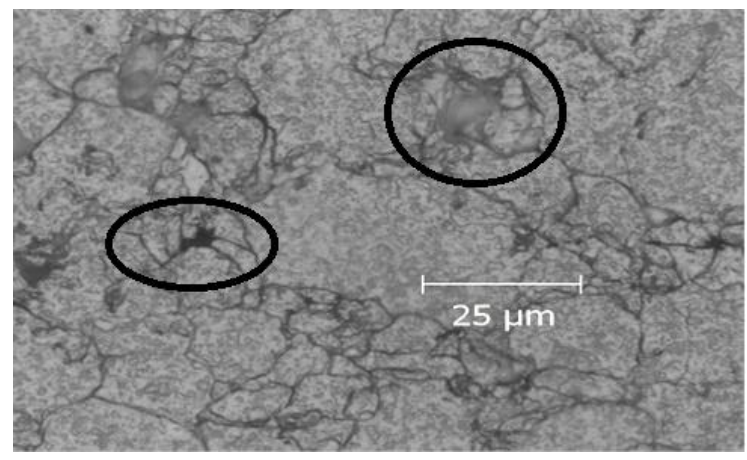

(ii)

Figure 3: SEM image of the reinforcement distribution of an Al with1.5 wt.\% MWCNT composite samples:

(i) casted samples (ii) powder metallurgy samples 
Girisha et al., Adv. Nan. Res.; Vol. 2 Issue 1, pp: 32-41, 2019

Figure 4 shows the fracture image obtained from SEM. it is one of the tools for understanding materials behaviour \& reinforcements to the fractures surface of the composites, it can fetch much information related to the material. Fracture surface investigations obtained by SEM provide information about the failure mechanism and the reinforcement role. The MWCNT pullout, crack bridging and MWCNT deflection are easily visible in the fracture surface SEM image, which provides information about the strengthening mechanisms involved.

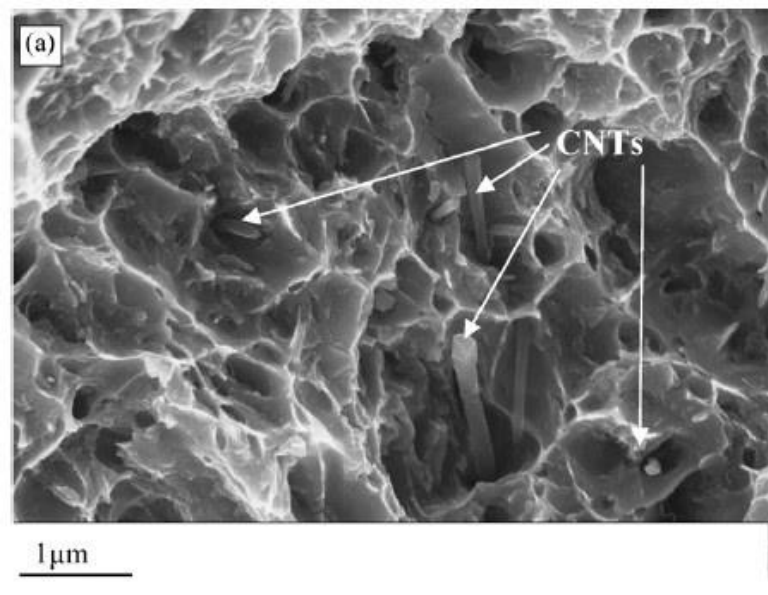

(a) $1.5 \mathrm{wt} \% \mathrm{Al}-\mathrm{MWCNT}$ casted sample

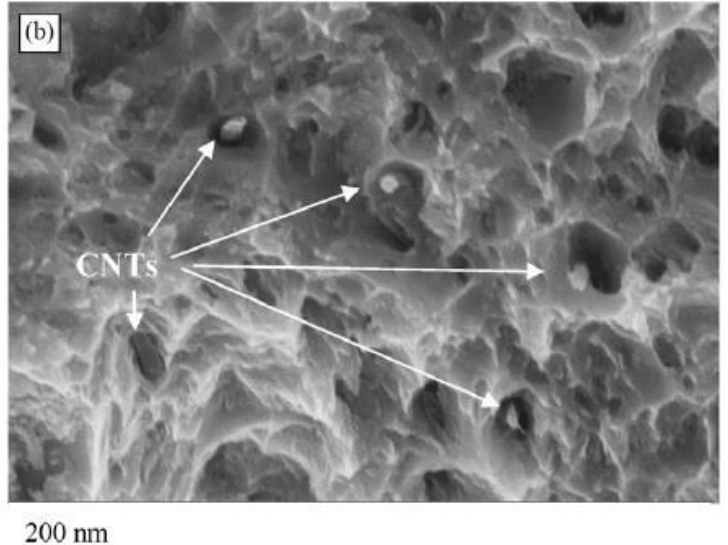

$200 \mathrm{~nm}$

(b) $1.5 \mathrm{wt} \% \mathrm{Al}-\mathrm{MWCNT}$ powder metallurgy sample

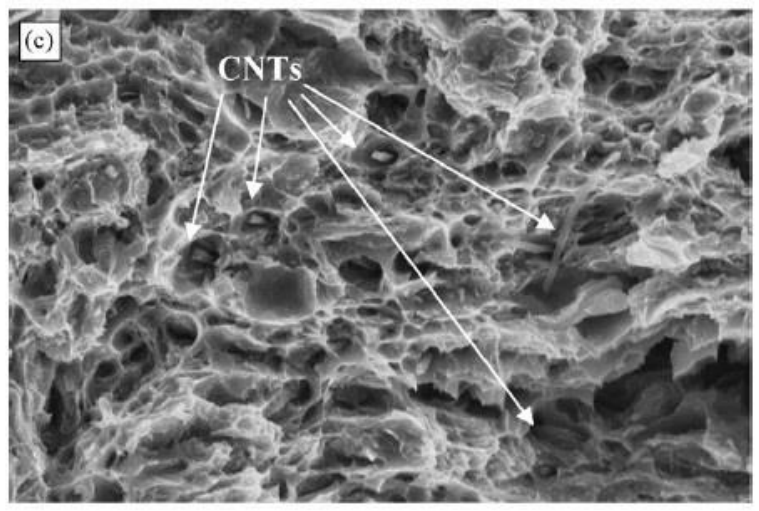

$\underline{1 \mu \mathrm{m}}$

(c) 2 wt.\% Al-MWCNT casted sample

Figure 4: Fracture surfaces of $1.5 \mathrm{wt} \% \mathrm{Al}-\mathrm{MWCNT}$ samples which shows individual MWCNTs dispersed in the matrix

Figure. 5 shows a heavily etched bulk composite sample that was not tensile tested. CNTs are adjusted in the direction of extrusion, which in the final composite can lead to anisotropic properties. In this sample, the voids formed around the CNTs are less present, proving that they are due to tensile testing.

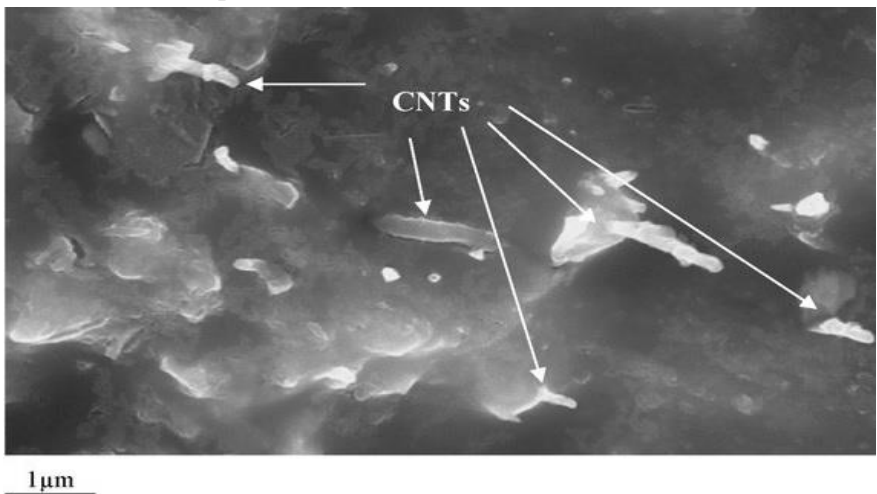

$1 \mu \mathrm{m}$

Figure 5: A cross section for $2 \mathrm{wt}$.\% Al-MWCNT extruded sample subjected to tensile testing and deeply etched showing individual MWCNTs aligned in the extrusion direction 
Mechanical Characterization of Nanomaterial Reinforced Aluminum-based Hybrid Nanocomposites

The results shown in Table 6 states that, Young's modulus for 1 wt. $\%$ MWCNT/GR reinforced commercial-purity $\mathrm{Al}$ composites increased by $14.67 \%$ for cast and $16.8 \%$ composite samples prepared by powder metallurgy route. Similarly, when yield strength is considered, it is observed that there is an increment of $20 \%$ and $21 \%$ for the composite samples prepared by casted and powder metallurgy routes respectively. For the $1.5 \mathrm{wt} \%$ the value of Young's modulus, yield strength, and ultimate strength of Al_/MWCNT nanocomposites, showed an increase of $21.22 \%, 24.29 \%$, and $22.8 \%$ for the casted composite samples, and $22.05 \%, 22.8 \%$, and $26 \%$ for the powder metallurgy samples, respectively.

Table 6: Tensile properties of Al-based MWCNT/GR hybrid nanocomposites

\begin{tabular}{|l|c|c|c|c|c|c|c|c|}
\hline \multirow{2}{*}{ Composition } & \multicolumn{2}{|c|}{$\begin{array}{c}\text { Young's } \\
\text { Modulus (GPa) }\end{array}$} & \multicolumn{2}{c|}{$\begin{array}{c}\text { Yield Strength } \\
\text { (MPa) }\end{array}$} & \multicolumn{2}{c|}{$\begin{array}{c}\text { Ultimate Tensile } \\
\text { Strength (MPa) }\end{array}$} & \multicolumn{2}{c|}{ \% Elongation } \\
\cline { 2 - 11 } & Casted & PM & Casted & PM & Casted & PM & Casted & PM \\
\hline Al/1wt.\% of MWCNTs \& GR & 78 & 82 & 98 & 100 & 152 & 162 & 9 & 8.32 \\
\hline Al/1.5wt.\% of MWCNTs \& GR & 84 & 91 & 99 & 112 & 159 & 170 & 7.9 & 7.1 \\
\hline Al/2wt.\% of MWCNTs \& GR & 85.5 & 94 & 98 & 114 & 162 & 167 & 8 & 7.6 \\
\hline
\end{tabular}

It was also seen for the $\mathrm{Al}$ composite strengthened by $2 \mathrm{wt} . \%$ MWCNT / GR. The Young's modulus and yield strength showed an increase from the matrix value for the casted samples by $22.7 \%$ and $22.75 \%$, and for the powder metallurgy samples by $20 \%$ and $26 \%$. The ultimate strength showed an improvement from the matrix value, however, when compared to the 1 wt. $\%$ and 1.5 wt. $\%$ Al / MWCNT / GR composites, there was a reduction. The increase in strength leads to a reduction in ductility. Compared to the powder metallurgy samples, the casted samples also showed good strength and rigidity. This is achieved by the uniform distribution of MWCNT \& GR reinforcements in PM technology compared with the casting method.

Early results of the GR reinforcement of MWCNT / GR alone cannot produce very high mechanical properties. If the ND is used together with MWCNT and GR as one of the reinforcements, very good mechanical properties are expected. [21]. Compared to the base metal, the mechanical properties of the composites are expected to be enhanced even with the low volume fraction of the reinforcement provided there is adequate wetting between the reinforcement and the matrix for load transfer. The tensile properties of Al_/MWCNT/ND nanocomposites are shown by table 7 the results depict that the composite Young's modulus and yield strength increases with an increase in the wt. $\%$ of the fiber, indicating a sufficient transfer of the load from the matrix to the fiber in samples prepared from powder metallurgy rout compared to the casted samples. The ultimate strength in the casted samples does not increase basically due to the nonhomogenous dispersion of the composite reinforcements as well as breakage of the sample in the grips during the tension test. In both the cases (casted and PM) The ductility of composite samples showed a decreasing trend with an increase in the wt.\% of reinforcement MWCNTs in nanocomposites $\mathrm{Al} \_/ \mathrm{MWCNT} / \mathrm{ND}$.

Table 7: Tensile properties of Al-based MWCNT/GR/ND hybrid nanocomposites

\begin{tabular}{|l|c|c|c|c|c|c|c|c|}
\hline \multirow{2}{*}{ Composition } & \multicolumn{2}{|c|}{$\begin{array}{c}\text { Young's Modulus } \\
\text { (GPa) }\end{array}$} & \multicolumn{2}{c|}{$\begin{array}{c}\text { Yield Strength } \\
(\mathrm{MPa})\end{array}$} & $\begin{array}{c}\text { Ultimate Tensile } \\
\text { Strength (MPa) }\end{array}$ & \multicolumn{2}{|c|}{$\begin{array}{c}\text { Elongation } \\
(\%)\end{array}$} \\
\cline { 2 - 11 } & Casted & PM & Casted & PM & Casted & PM & Casted & PM \\
\hline Al/1 wt.\% MWCNTs+GR+ND & 79 & 84 & 97 & 106 & 156 & 165 & 9.6 & 8 \\
\hline Al/1.5wt.\% WCNTs+GR+ND & 86 & 93 & 100 & 115 & 164 & 178 & 6.8 & 7 \\
\hline Al/2wt.\% WCNTs+GR+ND & 88 & 99 & 99 & 117 & 166 & 180 & 7 & 5.9 \\
\hline
\end{tabular}


Girisha et al., Adv. Nan. Res.; Vol. 2 Issue 1, pp: 32-41, 2019

For 1 wt. percent MWCNT / GR / ND strengthened commercial-purity Al composites, the results show that Young's module increased by 14 percent and 16.22 percent for the composite samples of cast and powder metallurgy respectively. The yield strength of the casted and powder metallurgy composite samples also improved by $21.3 \%$ and $22.23 \%$ respectively. For the $1.5 \mathrm{wt} . \%$ the value of Young's modulus, yield strength and ultimate strength for Al/MWCNT nanocomposites increased by $22.98 \%, 24 \%$ and $23.6 \%$ for the casted composite samples and by $22 \%, 23 \%$ and $26 \%$ for the samples prepared by powder metallurgy route.

For the Al composite reinforced by $2 \mathrm{wt.} \%$ of MWCNT / GR / ND, the Young modulus and yield strength increased from the matrix value by $24 \%$ and $25.8 \%$ for the cast samples and by $26 \%$ and $27.8 \%$ for the powder metallurgy samples. It showed improved results when the reinforcement used as ND was $2 \%$. The final strength showed a betterment in the matrix value compared to the Al/MWCNT \& Al/MWCNT/GR composites of $1 \mathrm{wt.} \%$ and $1.5 \mathrm{wt} . \%$. The strength increases lead to ductility reduction. The casted samples also showed good strength and stiffness compared with the powder metallurgy samples. Composites carrying $2 \mathrm{wt} . \%$ MWCNT/GR/ND resulted higher tensile strength because of the existence of less micro voids and good interface strength. In addition, due to the same reason, the strength of the samples prepared by casted $\mathrm{Al} / \mathrm{MWCNT} / \mathrm{GR} / \mathrm{ND}$ composites showed lower results compared to samples prepared by powder metallurgy route. The proper distribution of reinforcement throughout the matrix shows improved results in yield strength to the base matrix. When the temperature exceeds Al's melting point MWCNTs are also predicted to react with $\mathrm{Al}$.

\section{Conclusion}

The first part described the material used and the composite manufacturing processes. The casting and powder metallurgy technique are utilized to produce CNTs reinforced $\mathrm{Al}$ composites. The latter half reported the impact of 2 different reinforcements (hybrid) along with MWCNTs, namely GR and ND. The mechanical characteristics of Al_/MWCNT, Al_/MWCNT/GR and Al_/MWCNT/GR hybrid nanocomposites reported in the third part. The current research resulted that the addition of MWCNT, GR and ND into commercially pure $\mathrm{Al}$ nanocomposites manufactured by casting and powder metallurgy techniques improves the physico-mechanical properties of the composites, such as density, hardness, tensile strength and ductility. Compared to the $\mathrm{Al}$ matrix $\mathrm{Al} / \mathrm{MWCNT}$ nanocomposites showed an increment in the value of Young's modulus by $19 \%$ and $21 \%$ increment in the value of yield strength. The hybrid nanocomposites $\mathrm{Al} / \mathrm{MWCNT} / \mathrm{GR}$ and $\mathrm{Al} / \mathrm{MWCNT} / \mathrm{GR} / \mathrm{ND} 1.5 \mathrm{wt} . \%$ of the reinforcement showed betterment in yield strength by $21.65 \%$ and $23 \%$ respectively, Young's Modulus by $24 \%$ and $26 \%$ respectively when compared with the base Al matrix. Nanocomposites Al / MWCNT, Al / MWCNT / GR and Al / MWCNT / GR / ND were fabricated using powder metallurgy route. Compared to the casted samples, the mechanical characterization of these composite samples showed much better strength.1.5 wt. $\%$ fraction of reinforcement showed increases of $24 \%, 26 \%$, and $29.2 \%$ and $25 \%, 28 \%$, and $31 \%$ in yield strength compared with the $\mathrm{Al}$ matrix and casted samples, respectively.

\section{How to Cite this Article:}

G. L, M. Deshpande, G. Naik, and M. M R, "Mechanical Characterization of Nanomaterial Reinforced Aluminum-based Hybrid Nanocomposites", Adv. Nan. Res., vol. 2, no. 1, pp. 32-41, May 2019. doi:10.21467/anr.2.1.32-41

\section{References}

[1] H. W. Kroto, J. R. Heath, S. C. O”Brien, R. F. Curi and R. E. Smalley, “C60: Buckminester fullerene”, Nature, 318, pp. 162, Nov 1985 .

[2] W. Kratschmer, L. D. Lamb, K. Fostiropoulos and D. R. Huffman, “Solid C60: A new form of carbon”, Nature, 347, pp. 354-357, Sep 1990.

[3] Z. F. Ren, Z. P. Huang, J. W. Xu, J. H. Wang, P. Bush, M. P. Siegal, and P. N. Provencio, "Synthesis of large arrays of well-Aligned carbon nanotubes on glass", Science, Vol. 282, No. 5391, pp. 1105-1107, 1998

[4] M. M. J. Treacy, T. W. Ebbesen, and J. M. Gibson, "Exceptionally high Young"s modulus observed for individual carbon nanotubes", Nature, Vol. 381, pp. 678-681, 1996 
[5] Journet C., Maser W. K., Bernier P., Loiseau A., De la Chapelle M. L., Lefrant S., P. Deniard, R. Lee, and J. E. Fischer, “Large-scale production of single-walled carbon nanotubes by electric arc technique”, Nature, Vol. 388, No. 6644, pp. 756-758, 1997.

[6] S. I. Cha, K. T. Kim, S. N. Arshad, C. B. Mo and S. H. Hong, "Extraordinary Strengthening Effect of Carbon Nanotubes in MetalMatrix Nanocomposites Processed by Molecular-Level Mixing”, Advanced Materials, Vol. 17, No. 11, pp. 1377-1381, 2005.

[7] Umma A., Maleque M. A., iskandar I. Y. and Mohammed Y. A., "Carbon nanotube reinforced aluminum matrix nano-composite: a critical review”, Australian Journal of basic and applied sciences, Vol. 6, No. 12, pp. 69-75, 2012.

[8] Sumio Lijima, “Helical microtubules of graphitic carbon”, Nature, Vol. 354, No. 6348, pp. 56-58, Nov 1991.

[9] Toru Kuzumaki, Takuya Hayashi, Kun'ichi Miyazawa, Hideki Ichinose, Kunio Ito and Yoichi Ishida, "Processing of Ductile Carbon NanOtube/C60 Composite”, Materials Transactions, JIM, Vol. 39, No.5, PP. 674-577, 1998.

[10] K. S. Novoselov, V. I. Fal'ko, L. Colombo, P. R. Gellert, M. G. Schwab, K. Kim, “A Road Map For Graphene”, Nature, Vol. 490, No. 7419, pp. 192-200, Oct 2012.

[11] Sasha Stankovich, Dmitriy A. Dikin, Geoffrey H. B. Dommett, Kevin M. Kohlhaas, Eric J.Zimney, Eric A. Stach, Richard D. Piner, Sonbinh T. Nguyen and Rodney S. Ruoff, “Graphene Based Composite Materials”, Nature, Vol. 442, No. 7100, pp. 282-286, 2006.

[12] Prithu Mukhopadhyay and Rakesh K. Gupta, "Trends and frontiers in Graphene Based Polymer Nanocomposites", Plastic Engineering, Vol. 67, No. 1, PP. 32-42, 2011.

[13] M. Y. Shalaginov, G. V. Naik, S. Ishii, M. N. Slipchenko, A. Boltassev, and J. X. Cheng, "Characterization of nanodiamonds for metamaterial applications", Applied physics B, Vol. 105, No. 2, pp. 191-195, September 2010.

[14] T. S. Kurkin, A. N. Ozerin, A. S. Kechek”yan, O. T. Gritsenko, L. A. Ozerina, G. G. Alkhanishvili, V. G. Sushchev, and V. Yu. Dolmatov, "The structure and properties of polymer composite fibers based on poly (vinyl alcohol) and nanodiamond of detonation synthesis”, Nanotechnologies in Russia, Vol. 5, No. 5-6, pp. 340-351, June 2010.

[15] S. Mitura, "Nanodiamonds", Journal of Achievements in Materials and Manufacturing Engineering, Vol. 24, No. 1, pp. 166-171, September 2007.

[16] H. Kaftelen, and M. L. Ovecoglu, "Microstructural characterization and wear properties of ultra-dispersed nanodiamond (UDD) reinforced Al matrix composites fabricated by ball-milling and sintering”, Journal of Composite Materials, Vol. 46, No. 13, pp. 15211534, Jan 2012.

[17] V. V. Danilenko, “On the History of the Nanodiamond Synthesis”, Physics of the Solid State, Vol. 46, pp. 595-598, 2004.

[18] R. George, K. T. Kashyap, R. Rahul, S. Yamdagni, "Strengthening in carbon nanotibe/aluminium (CNT/Al) composites”, Scripta Materialia, Vol. 53, No. 10, pp. 1159-1163, 2005.

[19] CailuXu, Bingqing Wei, Ji Liang and Dehai Wu, "Structure and Electrical Resistivity of the Al-Carbon Nanotube Composites", Metals and Materials, Vol. 4, No. 4, pp. 620-623, 1998.

[20] L. Y. Jiang, Y. Huang, H. Jiang, G. Ravichandran, H. Gao, K. C. Hwang, B. Liu, “A cohesive law for carbon nanotubes/polymer interfaces based on the van der Waals force”, Journal of the Mechanics and Physics of Solids, Vol. 54, No. 11, pp. 2436-2452, 2006.

[21] P. J. F. Harris, “Carbon nanotubes composites”, International Materials, Vol. 49, No. 1, pp. 31-43, 2004.

[22] Ramanujamsarathi, Ravindrakumar Sahu, and Machael G. Danikas, "Understanding the Mechanical Properties of Epoxy Nanocomposite Insulating Materials”, Journal of Electrical Engineering, Vol. 60, No. 6, pp. 358-361, 2009.

[23] K. Eswar Prasad, Barun Das, Urmimala Maitra, Upadrasta Ramamurty and CNR Rao, "Extraordinary synergy in the mechanical properties of polymer matrix composites reinforced with 2 nanocarbons", Proceedings of the National Academy of Sciences, Vol. 106, No. 32, pp. 1-4, 2009.

[24] Mahendra Bhoopathi M., K. P. Arulshri and N. Iyandurai, "Evaluation of mechanical properties of aluminum alloy 2024 reinforced with silicon carbide and fly ash hybrid metal matrix composites”, American Journal of Applied Sciences, Vol. 10, No. 3, pp. 219$229,2013$.

[25] M. N. Gururaj, and A. N. Hari Rao, “A Review on recent applications and future prospectus of hybrid composites”, International Journal Computing and Engineering, Vol. 1, No. 6, pp. 352-355, Jan 2012.

[26] J. JenixRinol, D. Chandramohan, and K. S. Sucitharan, “An Overview on Development of Aluminium Metal Matrix Composites with Hybrid Reinforcement”, International journal of science and research, Vol. 1, pp. 196-203, Dec 2012.

Publish your research article in AIJR journalsOnline Submission and Tracking Peer-Reviewed

$\checkmark$ Rapid decision

$\checkmark \quad$ Immediate Publication after acceptance

$\checkmark$ Articles freely available online

$\checkmark \quad$ Retain full copyright of your article.

Submit your article at journals.aijr.in
Publish your books with AIJR publisher-

$\checkmark$ Publish with ISBN and DOI.

$\checkmark$ Publish Thesis/Dissertation as Monograph.

$\checkmark$ Publish Book Monograph.

$\checkmark$ Publish Edited Volume/ Book.

$\checkmark$ Publish Conference Proceedings

$\checkmark \quad$ Retain full copyright of your books. Submit your manuscript at books.aijr.org 